\title{
PARADA CARDIORRESPIRATÓRIA E ENFERMAGEM: O CONHECIMENTO ACERCA DO SUPORTE BÁSICO DE VIDA*
}

\author{
Cristiele Aparecida Alves ${ }^{1}$, Cinthia Natalia Silva Barbosa ${ }^{1}$, Heloisa Turcatto Gimenes Faria ${ }^{2}$
}

\begin{abstract}
RESUMO: Estudo descritivo e transversal cujo objetivo foi avaliar o conhecimento teórico dos enfermeiros de um hospital do interior de Minas Gerais-Brasil acerca do suporte básico de vida utilizado no atendimento à parada cardiorrespiratória. A amostra foi constituída por 16 enfermeiros, para a coleta de dados utilizou-se instrumento construído com base nas recomendações da American Heart Association para ressuscitação cardiopulmonar. Os resultados mostraram lacunas no conhecimento acerca dos ritmos identificados na parada cardiorrespiratória, sequência de atendimento, número de ciclos compressão versus ventilação, abertura das vias aéreas, local de colocação das pás do desfibrilador, procedimento a ser realizado imediatamente após o choque, e cargas, em joules, recomendadas para a desfibrilação. Recomenda-se a reavaliação e capacitação contínua dos enfermeiros para adequado desempenho no atendimento em parada cardiorrespiratória, contribuindo para a sobrevida da população. DESCRITORES: Educação em enfermagem; Parada cardíaca; Conhecimento; Ressuscitação cardiopulmonar.
\end{abstract}

\section{CARDIORESPIRATORY ARREST AND NURSING: THE KNOWLEDGE ON BASIC LIFE SUPPORT}

\begin{abstract}
The objective of this descriptive and cross-sectional study was to assess the theoretical knowledge of the nurses in a hospital in the state of Minas Gerais regarding the basic life support used in attending cardiorespiratory arrest. The sample was constituted by 16 nurses, and an instrument constructed based on the recommendations of the American Heart Association for cardio-pulmonary resuscitation was used for data collection. The results showed gaps in the knowledge on the rhythms identified in cardio-respiratory arrest, the sequence of steps, number of cycles versus ventilation, opening of the airways, where to place the defibrillator electrode pads, the procedure to be undertaken immediately after the shock, and the loads, in joules, recommended for the defibrillation. The re-assessment and continuous training of the nurses is recommended, for their adequate performance in treating cardiorespiratory arrest, contributing to the population's survival. DESCRIPTORS: Nursing education; Cardiac arrest; Knowledge; Cardio-pulmonary resuscitation.

\section{PARADA CARDIORRESPIRATORIA Y ENFERMERÍA: EL CONOCIMIENTO ACERCA DEL SOPORTE BÁSICO DE VIDA}

RESUMEN: Estudio descriptivo y transversal cuyo objetivo fue evaluar el conocimiento teórico de los enfermeros de un hospital del interior de Minas Gerais, Brasil, acerca del soporte básico de vida utilizado en el atendimiento a la parada cardiorrespiratoria. La muestra fue constituida por 16 enfermeros y, para obtener los datos, fue utilizado instrumento construido con base en las recomendaciones de American Heart Association para resucitación cardiopulmonar. Los resultados apuntan huecos en el conocimiento acerca de los ritmos identificados en la parada cardiorrespiratoria, secuencia de atendimiento, número de ciclos compresión versus ventilación, apertura de las vías aéreas, local de colocación del desfibrilador, procedimiento a ser realizado inmediatamente después de las descargas eléctricas, y cargas, en joules, recomendadas para la desfibrilación. Se sugiere nueva evaluación y capacitación continua de los enfermeros para adecuado desempeño en el atendimiento en parada cardiorrespiratoria, contribuyendo para la sobrevida de la población. DESCRIPTORES: Educación en enfermería; Parada cardíaca; Conocimiento; Resucitación cardiopulmonar.

*Estraído do Trabalho de Conclusão de Curso de Graduação em Enfermagem ' Parada cardiorresppiratória e enfermagem: o conhecimento acerca do suporte básico de vida' apresentado ao Libertas Faculdades Integradas de São Sebastião do Paraíso, em 2012.

${ }^{1}$ Enfermeira

${ }^{2}$ Enfermeira. Doutora em Enfermagem. Professora do Curso de Graduação em Enfermagem da Libertas Faculdades Integradas de São Sebastião do Paraíso. 


\section{INTRODUÇÃO}

A luta pela manutenção da vida, que ocorre nas diversas situações de urgência e emergência, representa o princípio básico e fundamental que norteia o desenvolvimento técnico-científico na área da saúde. Entre as emergências que ameaçam a vida, a parada cardiorrespiratória (PCR) apresenta-se como a mais temida, uma vez que a chance de sobreviver está diretamente relacionada ao atendimento rápido, seguro e eficaz.

No atendimento à $\mathrm{PCR}$, os primeiros indícios de surgimento das manobras de ressuscitação cardiopulmonar (RCP) originaram-se na Medicina dos Hebreus. Com o tempo, essas manobras foram aprimoradas, o que possibilitou a elaboração de normas, diretrizes e padronização no atendimento, com consequente aumento da sobrevida dos indivíduos acometidos, bem como a redução de sequelas ${ }^{(1)}$.

Segundo a American Heart Association (2), o atendimento à PCR divide-se em Suporte Básico de Vida (SBV), que compreende um conjunto de técnicas sequenciais caracterizadas por compressões torácicas, abertura das vias aéreas, respiração artificial e desfibrilação; e Suporte Avançado de Vida (SAV) que consiste na manutenção do SBV, com a administração de medicamentos e o tratamento da causa da PCR.

Nesta direção, ao considerar a PCR como uma emergência clínica, na qual o objetivo do tratamento consiste em preservar a vida, restabelecer a saúde, aliviar o sofrimento e diminuir incapacidades, o atendimento deve ser realizado por equipe competente, qualificada e apta para realizar tal tarefa. Neste contexto destaca-se a figura do enfermeiro, profissional muitas vezes responsável por reconhecer a PCR, iniciar o SBV e auxiliar no SAV.

Assim, para atendimento eficaz e seguro os profissionais devem ter preparo e conhecimento sobre as manobras de reanimação, uma vez que a falta de conhecimento traz como consequência um agir inadequado, com prejuízos na assistência prestada e sobrevida. Atitudes e comportamentos dos enfermeiros podem influenciar a rapidez e o nível de envolvimento da equipe nas diversas situações de emergência que incluem os episódios de $\mathrm{PCR}^{(3-5)}$. Estudos apontam que a sobrevida, após uma PCR, varia de dois a 49\%, e que esses valores estão diretamente relacionados ao ritmo cardíaco inicial e ao início precoce da RCP. Ainda, a sobrevivência pode dobrar ou triplicar quando as manobras de ressuscitação são realizadas com qualidade $^{(6-7)}$.
Frente ao exposto, tornam-se imprescindíveis estudos que avaliem o conhecimento dos enfermeiros acerca das manobras de ressuscitação, uma vez que as diretrizes que norteiam o atendimento à PCR mudam a cada cinco anos, o que exige, desses profissionais, atualização constante na área. Ainda, estudos possibilitam aos serviços de saúde a elaboração de estratégias de ensino voltadas às reais dificuldades encontradas pelos profissionais de saúde na assistência à PCR. Neste contexto, foi objetivo da presente pesquisa avaliar o conhecimento teórico dos enfermeiros de um hospital do interior de Minas Gerais acerca do suporte básico de vida utilizado no atendimento à PCR.

\section{MÉTODO}

Estudo descritivo e transversal, realizado em um hospital do interior de Minas Gerais, em maio de 2012. Dos 30 enfermeiros do quadro de funcionários do hospital em estudo, foram incluídos os 17 que compunham a equipe dos setores de atendimento adulto, ou seja, enfermarias de clínica médica e cirúrgica, unidade de terapia intensiva, hemodiálise, centro cirúrgico e unidade de pronto atendimento. Desses, um foi excluído por estar em férias no mês do estudo, totalizando16 enfermeiros participantes.

O levantamento de dados foi realizado por meio de questionário contendo duas partes: a primeira relacionada às variáveis sociodemográficas e, a segunda, o conhecimento sobre parada cardiorrespiratória e suporte básico de vida, elaborada com base no Guidelines 2010 para Ressuscitação Cardiopulmonar e Atendimento Cardiovascular de Emergência (2).

Após aprovação do Comitê de Ética em Pesquisa da Fundação de Ensino Superior de Passos - MG (Parecer n. 26 2012), os dados foram coletados pelos pesquisadores por meio de entrevista individual dirigida por questionário, previamente agendada e realizada no respectivo turno de trabalho, conforme disponibilidade do participante, em local reservado e após assinatura do termo de consentimento livre e esclarecido.

Os dados foram inseridos em planilhas no programa Excel e as análises foram realizadas mediante estatística descritiva, com valores de frequência absoluta e relativa, para as variáveis categóricas, e média, desvio padrão, valores mínimo e máximo para as variáveis contínuas. 


\section{RESULTADOS}

Em relação às variáveis sociodemográficas, a idade variou de 25 a 39 anos, com média e desvio padrão de $29,4(5,4)$ anos e predomínio do sexo feminino $(87,5 \%)$.

Dos 16 participantes, $43,8 \%$ referiram apresentar algum grau de dificuldade no atendimento à PCR. Dentre elas, destacam-se o despreparo da equipe $(28,7 \%)$ e o uso do desfibrilador $(28,7 \%)$. No que se refere ao conhecimento acerca do diagnóstico de PCR, $81,3 \%$ responderam corretamente quanto às condutas que devem ser realizadas logo após a identificação da PCR, 18,7\% responderam incorretamente.

Entre os participantes, $25 \%$ referiram corretamente os ritmos identificados na PCR, 62,5\% citaram a assistolia; $18,7 \%$ não souberam responder a essa pergunta. Em relação aos ritmos identificados e que respondem ao choque como tratamento, $31,3 \%$ responderam corretamente, $31,3 \%$ incorretamente, $12,5 \%$ acertaram apenas um dos ritmos e $6,2 \%$ não responderam.

No que se refere ao SBV, $50 \%$ responderam corretamente quanto à sequencia de atendimento, que inclui primeiro circulação, seguida por abertura de vias aéreas, respiração e desfibrilação. Quanto à relação compressão-ventilação, a maioria (75\%) respondeu corretamente, sendo 30 compressões para duas ventilações, independente do número de socorristas. Em contrapartida, em relação à quantidade de ciclos compressão-ventilação, 56,2\% não responderam corretamente. Uma vez identificada a PCR, 68,7\% dos participantes afirmaram que as compressões torácicas devem ser iniciadas imediatamente ao pedir ajuda e posicionar a vítima em decúbito dorsal. Em relação às compressões torácicas, a maioria respondeu corretamente quanto ao local de posicionamento das mãos no tórax da vítima, à profundidade das compressões sobre o tórax, e à quantidade de compressões que devem ser realizadas por minuto durante o atendimento à PCR (Tabela 1).

Tabela 1 - Conhecimento da técnica da compressão torácica realizada no atendimento à parada cardiorrespiratória entre enfermeiros. São Sebastião do Paraíso, 2012

\begin{tabular}{lccc}
\hline \multicolumn{1}{c}{ Técnica de compressão } & $\begin{array}{c}\text { Correta } \\
\text { n (\%) }\end{array}$ & $\begin{array}{c}\text { Incorreta } \\
\mathbf{n ~ ( \% )}\end{array}$ & $\begin{array}{c}\text { Não sabe } \\
\text { n (\%) }\end{array}$ \\
\hline Posicionamento das mãos no tórax da vítima & $9(56,2)$ & $6(37,5)$ & $1(6,3)$ \\
Profundidade das compressões sobre o tórax da vitima & $9(56,2)$ & $4(25,0)$ & $3(18,8)$ \\
Quantidade de compressões por minuto & $10(62,5)$ & $6(37,5)$ & $0(0)$ \\
\hline
\end{tabular}

Ao analisar a sequência correta de abertura das vias aéreas, $43,8 \%$ não acertaram a resposta, 31,2\% responderam corretamente e $25 \%$ não souberam responder à pergunta. Quanto ao número de ventilações oferecidas entre as compressões torácicas, a maioria $(56,2 \%)$ respondeu corretamente, ou seja, duas ventilações, com duração de um segundo cada.

Em relação ao uso do desfibrilador, a maioria (75\%) respondeu corretamente quanto à sequência que deve ser realizada e 50\% acertaram o local de colocação das pás. Em contrapartida, $87,5 \%$ dos participantes não assinalaram a alternativa correta quando questionados acerca do procedimento que deve ser realizado logo após o choque, ou seja, reiniciar imediatamente as compressões torácicas. Ao questionar a carga que deve ser utilizada nos desfibriladores manuais, $50 \%$ responderam corretamente quanto aos desfibriladores monofásicos e 43,7\% quanto aos desfibriladores bifásicos (Tabela 2).

Tabela 2 - Conhecimento sobre uso do desfibrilador no atendimento à parada cardiorrespiratória entre enfermeiros. São Sebastião do Paraíso, 2012

\begin{tabular}{lccc}
\hline \multicolumn{1}{c}{ Técnica de utilização do desfibrilador } & $\begin{array}{c}\text { Correta } \\
\text { n (\%) }\end{array}$ & $\begin{array}{c}\text { Incorreta } \\
\text { n (\%) }\end{array}$ & $\begin{array}{c}\text { Não sabe } \\
\text { n (\%) }\end{array}$ \\
\hline Sequência de utilização & $12(75)$ & $2(12,5)$ & $2(12,5)$ \\
Posição das pás na desfibrilação & $8(50)$ & $5(31,2)$ & $3(18,8)$ \\
Procedimento a ser realizado após o choque & $2(12,5)$ & $14(87,5)$ & $0(0)$ \\
Carga em joules do desfibrilador monofásico & $8(50)$ & $6(37,5)$ & $2(12,5)$ \\
Carga em joules do desfibrilador bifásico & $7(43,7)$ & $6(37,5)$ & $3(18,8)$ \\
\hline
\end{tabular}

Cogitare Enferm. 2013 Abr/Jun; 18(2):296-301 


\section{DISCUSSÃO}

Estudos demonstraram que o conhecimento e as habilidades de como proceder diante da PCR, pelos profissionais de saúde, são escassos e o treinamento torna-se cada vez mais importante para direcionar as ações durante o atendimento prestado ${ }^{(8-9)}$. Assim, investir em treinamento, em especial aos enfermeiros que prestam assistência direta às pessoas em PCR, e a elaboração de protocolos de atendimento, pode proporcionar menor risco, consequentemente, maior segurança à pessoa acometida. Ao analisar as ocorrências iatrogênicas, a falta de conhecimento e habilidades para o atendimento é o mais identificado, seguido por problemas relacionados aos equipamentos, o que afirma os achados em relação às dificuldades encontradas pelos enfermeiros entrevistados, ou seja, o despreparo da equipe e o uso do desfibrilador ${ }^{(10)}$. $\mathrm{Na}$ presente pesquisa, ao analisar o conhecimento acerca do diagnóstico da PCR, 81,3\% responderam corretamente, o que difere de outros estudos ${ }^{(3,11)}$.

Antes de se iniciar o atendimento à PCR, é necessário avaliar primeiramente a responsividade da vítima, seguido pela avaliação do pulso carotídeo. A identificação precoce desses sinais possibilita intervenção mais rápida, o que proporciona maior sobrevida aos indivíduos acometidos ${ }^{(2)}$. O prognóstico, após o episódio de PCR, está diretamente relacionado com o diagnóstico e com o intervalo de tempo entre esse evento e o início das manobras de ressuscitação. Assim, quando há intervenção, a taxa de sobrevida é de $75 \%$ nos primeiros quatro minutos, $15 \%$ entre quatro a 12 minutos e apenas $5 \%$ após 15 minutos $^{(12)}$.

No ambiente hospitalar, geralmente, os primeiros profissionais que respondem ao atendimento de PCR são os enfermeiros, que iniciam as manobras do SBV enquanto aguardam o SAV. A rapidez, competência e, sincronismo da equipe de enfermagem são fatores que contribuem para o sucesso da RCP e sobrevida do indivíduo $^{(5)}$. Assim, torna-se fundamental o conhecimento pelos enfermeiros acerca da sequência preconizada de atendimento à PCR. No presente estudo, $50 \%$ dos enfermeiros entrevistados conheciam a sequencia de atendimento, o que, apesar de insuficiente, ainda está acima da média encontrada em outras pesquisas ${ }^{(3,13)}$.

Além do conhecimento em relação à sequência de atendimento, segundo a literatura, é fundamental que a equipe envolvida no atendimento à PCR também saiba reconhecer os ritmos cardíacos, uma vez que, para os ritmos chocáveis, a desfibrilação é o procedi- mento primordial e deve ser realizada o mais rápido possível $^{(14)}$. Fato esse preocupante uma vez que na presente investigação apenas $25 \%$ dos enfermeiros entrevistados referiram corretamente os quatro ritmos, o que corrobora com outros estudos ${ }^{(11,13)}$.

Uma vez iniciado o atendimento, as compressões torácicas são fundamentais uma vez que geram fornecimento de fluxo sanguíneo, consequentemente, levam oxigênio e energia para órgãos críticos, como coração e cérebro. Nessa direção, a compressão torácica, quando realizada em local, profundidade e frequência corretos, está diretamente relacionada ao aumento da sobrevida das pessoas em PCR ${ }^{(2)}$. Importante ressaltar que no estudo em questão, a maioria dos enfermeiros mostrou conhecimento acerca da técnica de compressão torácica utilizada no SBV.

Em relação à abertura das vias aéreas, na ausência de suspeita ou confirmação de lesão cervical, a sequência correta consiste em inclinar a cabeça e elevar o queixo. No presente estudo, apenas $31,2 \%$ responderam corretamente. Pesquisa realizado em Recife-Pernambuco, com o objetivo de avaliar o impacto de um programa permanente de treinamento em SBV e SAV entre profissionais de enfermagem, identificou baixo nível de conhecimento sobre o manuseio das vias aéreas ${ }^{(15)}$. Dentre as técnicas que devem ser realizadas inclui: a abertura das vias aéreas, seguida pela retirada de qualquer objeto da orofaringe que possa estar obstruindo a passagem de ar, e a colocação da cânula de Guedel na presença de relaxamento do músculo da língua. Após esses procedimentos, recomenda-se verificar a presença, ou não, de movimentos respiratórios ${ }^{(2)}$.

Em relação ao uso do desfibrilador, a maioria respondeu corretamente quanto à sequência que deve ser realizada na sua utilização. Em contrapartida, somente $50 \%$ dos enfermeiros acertaram o local correto de colocação das pás e a carga utilizada nos desfibriladores monofásicos. Em estudos utilizados para comparação dos dados, essas porcentagens foram ainda mais baixas, o que é preocupante diante da importância da desfibrilação precoce para o sucesso da $\operatorname{RCP}^{(3-4,13,15)}$.

Vale ressaltar que durante a coleta de dados, pode-se observar que ao serem questionados a respeito dos desfibriladores, muitos participantes não sabiam a diferença entre desfibriladores monofásicos e bifásicos, o que pode justificar a porcentagem de erros em relação à carga utilizada para cada um deles.

Na década de 1980 a Associação Americana de Enfermagem estabeleceu como responsabilidade da equipe de enfermagem no atendimento de emergência a preparação dos materiais para intubação endotraqueal, aspiração, 
monitorização cardíaca e desfibrilação, auxiliando o profissional médico na execução desses procedimentos ${ }^{(15)}$. Portanto, segundo a referida Associação, o enfermeiro não está autorizado a utilizar o desfibrilador convencional na ausência de um médico. Ao analisar o procedimento realizado após o choque, apenas $12,5 \%$ dos enfermeiros referiram corretamente iniciar as compressões torácicas. Esse resultado pode ser justificado pelo fato de que muitos profissionais que atendem à PCR, por desconhecimento, veem o choque como a última opção de tratamento para salvar a vida da pessoa acometida, não reiniciando as compressões imediatamente após o choque.

Nessa direção, associações internacionais demonstram preocupação e interesse com as questões de divulgação, padronização e treinamento para atualização dos profissionais de saúde para o atendimento à $\mathrm{PCR}^{(8)}$. $\mathrm{O}$ atendimento adequado da PCR exige ação rápida e harmoniosa das pessoas envolvidas, a fim de priorizar a necessidade de uma equipe bem treinada, que possa atuar de forma efetiva, uma vez que, evita a desorganização e a ineficiência do atendimento ${ }^{(10)}$.

Os episódios de PCR são, na maioria das vezes, dramáticos e requerem dos profissionais várias habilidades, o que está relacionado às chances de sucesso no atendimento ${ }^{(16)}$. Assim, é fundamental que os enfermeiros, como líderes e orientadores/educadores da equipe de enfermagem, estejam atualizados em relação às diretrizes internacionais ${ }^{(2)}$ que norteiam o atendimento à PCR. Essa atualização possibilita maior segurança, conhecimento e habilidades no atendimento e, consequentemente, qualidade na assistência prestada. Para que essas orientações sejam seguidas, não é preciso adquirir novos equipamentos, mas sim programas de educação eficientes, com base nas reais necessidades dos profissionais envolvidos ${ }^{(13,16)}$.

Estudo de revisão com o objetivo de analisar a produção científica sobre PCR em âmbito intra-hospitalar identificou a necessidade de manter o desenvolvimento de ações voltadas para qualificar a RCP e prevenir a PCR, através de programas de educação, com vistas ao aumento da sobrevivência e da qualidade de vida das pessoas $^{(17)}$. De acordo com a literatura, programas de capacitação devem ser aplicados, preferencialmente, em intervalos não superiores a seis meses, e afirma que a retenção do conhecimento teórico e a manutenção das habilidades técnicas estão diretamente relacionadas com a experiência e a aplicação na prática. Assim, recomenda-se que os cenários dos cursos devem se aproximar da realidade da situação do atendimento da PCR em que os profissionais a vivenciam ${ }^{(5,8,18-20)}$.

\section{CONCLUSÃO}

Diante do exposto, torna-se fundamental o incentivo à reavaliação e capacitação contínua de enfermeiros, principalmente em se tratando do atendimento à PCR. Pois, como evidenciado no estudo, a maioria dos enfermeiros, apesar de reconhecer a importância do tema, não tinha conhecimento acerca de alguns procedimentos preconizados pelas diretrizes atuais de ressuscitação cardiopulmonar, bem como a sequência ideal de atendimento.

Ao considerar que a adequada ressuscitação realizada pelo enfermeiro é fator determinante nos índices de sobrevivência dos episódios de PCR, e que ele é normalmente o primeiro profissional a se deparar com esse evento, a educação permanente permitirá restaurar o processo de vida, e não apenas prolongar o processo de morte dos indivíduos. Nesse contexto, recomenda-se aos serviços de saúde realizar treinamento periódico em RCP com a finalidade de capacitar as equipes, em especial o enfermeiro, para atendimento rápido, seguro e eficaz, dentro do que é preconizado, e manter a homogeneidade das condutas entre as equipes.

\section{REFERÊNCIAS}

1. Leitão EA, Cortez MSM, Carvalho DV, Magalhães Junior HM. Atualização em ressuscitação cardiopulmonar. Rev. Min. Saúde Púb. [Internet] 2005;5(6) [acesso em 20 dez 2011]. Disponível: http://www.esp.mg.gov.br/ wp-content/uploads/2009/07/revista06.pdf

2. American Heart Association. Destaques das Diretrizes da American Heart Association 2010 para RCP e ACE. [Internet] 2010 [acesso em 17 nov 2011]. Disponível: http://www.heart.org/idc/groups/heartpublic/@wcm/@ ecc/documents/downloadable/ucm_317343.pdf

3. Almeida AO, Araújo IE, Dalri MCB, Araujo S. Conhecimento teórico dos enfermeiros sobre parada e ressuscitação cardiopulmonar, em unidadesnão hospitalares de atendimento à urgência e emergência. Rev. Latino-Am. Enfermagem. [Internet] 2011;19(2) [acesso em 18 jun 2012]. Disponível: http://www.scielo.br/pdf/rlae/v19n2/pt_06.pdf

4. Bertoglio VM, Azzolin K, Souza EN, Rabelo ER. Tempo decorrido do treinamento em parada cardiorrespiratória e o impacto no conhecimento teórico de enfermeiros. Rev. Gaúcha Enferm. [Internet] 2008;29(3) [acesso em 10 jun 2012]. Disponível: http://seer.ufrgs.br/ RevistaGauchadeEnfermagem/article/view/6774/4077

5. MokhtariNori J, Saghafinia M, KalantarMotamedi $\mathrm{MH}$, KhademolHosseini SM. CPR training for nurses: howoftenis it necessary? Iran. Red Crescent Med. 
J. [Internet] 2012;14(2) [acesso em 29 mar 2013]. Disponível: http://www.ncbi.nlm.nih.gov/pmc/articles/ PMC3372042/

6. Horsted T, Rasmussen LS, Meyhoff CS, Nielsen SL. Long-termprognosisafterout-of hospital cardiacarrest. J. Resucitation. [Internet] 2007;72(2) [acesso em 29 mar 2013]. Disponível: http://www.resuscitationjournal. com/article/S0300-9572(06)00344-3/pdf

7. Dalri MCB, Araújo IEM, Silveira RCCP, Canini SRMS, Cyrillo RMZ. Novas diretrizes da ressuscitação cardiopulmonar. Rev. Latino-Am. Enfermagem. [Internet] 2008;16(6) [acesso em 29 mar 2013]. Disponível: http://dx.doi.org/10.1590/S010411692008000600020.

8. Bellan MC, Araújo IEM, Araújo S. Capacitação teórica do enfermeiro para o atendimento da parada cardiorrespiratória. Rev. bras. enferm. [Internet] 2010;63(6) [acesso em 10 jun 2012]. Disponível: http:// dx.doi.org/10.1590/S0034-71672010000600023

9. Pembeci K, Yildirim A, Turan E, Buget M, Camci $\mathrm{E}$, Senturk $\mathrm{M}$ et al. Assessment of the success of cardiopulmonar resuscitation attempts performed ina Turkish university hospital. Resuscitation. [Internet] 2006;68(2) [acesso em 18 jun 2012]. Disponível: http://www.resuscitationjournal.com/article/S03009572(05)00288-1/fulltext

10. Silva SC, Padilha KG. Parada cardiorrespiratória na unidade de terapia intensiva: considerações teóricas sobre os fatores relacionados às ocorrências iatrogênicas. Rev Esc Enferm USP. [Internet] 2001;35(4) [acesso em 10 jun 2012]. Disponível: http://dx.doi. org/10.1590/S0080-62342001000400008.

11. Zanini J, Nascimento ERP, Barra DCC. Parada e reanimação cardiorrespiratória: Conhecimentos da equipe de enfermagem em unidade de terapia intensiva. Rev. Bras. Ter. Intensiva. [Internet] 2006;18(2) [acesso em 10 jun 2012]. Disponível: http://dx.doi.org/10.1590/ S0103-507X2006000200007.

12. Bueno LO, Guimarães HP, Lopes RD, Schmeider AP, Leal PHR, Senna APR et al. Avaliação dos índices prognósticos SOPA e MODS em pacientes após parada cardiorrespiratória em unidade de terapia intensiva geral. Rev. Bras. Ter. Intensiva. [Internet] 2005;17(3) [acesso em 18 jun 2012]. Disponível: http://rbti.org.br/ rbti/download/artigo_2010616171158.pdf

13. Araújo KA, Jacquet $P$, Santos SS, Almeida V, Nogueira SF. Reconhecimento da parada cardiorrespiratória em adultos: nível de conhecimento dos enfermeiros de um pronto-socorro municipal na cidade de São Paulo. J. Health Sci. Inst. [Internet] 2008;26(2) [acesso em 10 jun 2012]. Disponível: http://www.unip.br/comunicacao/ publicacoes/ics/edicoes/2008/02_abr_jun/V26_ N2_2008_p183-190.pdf

14. Murphy M, Fitzsimons D. Does attendance at an immediate life support course influence nurses' skill deployment during cardiac arrest? Resuscitation. [Internet] 2004;62(1) [acesso em 2012 Jun 18]. Disponível: http://www.resuscitationjournal.com/ article/S0300-9572(04)00078-4/fulltext

15. Lima SG, Macedo LA, Vidal ML, Sá MPBO. Educação permanente em SBV e SAV: impacto no conhecimento dos profissionais de enfermagem. Arq. Bras. Cardiol. [Internet] 2009;93(6) [acesso em 29 mar 2013]. Disponível: http://dx.doi.org/10.1590/S0066782X2009001200012.

16. Källestedt MLS, Berglund A, Herlitz J, Leppert J, Enlund M. The impact of CPR and AED training on healthcare professionals'self-perceived attitudes to performing resuscitation. Scand J Trauma Resusc Emerg Med. [Internet] 2012;20(26) [acesso em 29 mar 2013]. Disponível: http://www.ncbi.nlm.nih.gov/pmc/ articles/PMC3352321/

17. Luzia MF, Lucena AF. Parada cardiorrespiratória do paciente adulto no âmbito intra-hospitalar: subsídios para a enfermagem. Rev. Gaúcha Enferm. [Internet] 2009;30(2) [acesso em 29 mar 2013]. Disponível: http://seer.ufrgs.br/ RevistaGauchadeEnfermagem/article/view/5638/6692

18. Brião RC, Souza EN, Castro RA, Rabelo ER. Estudo de coorte para avaliar o desempenho da equipe de enfermagem em teste teórico, após treinamento em parada cardiorrespiratória. Rev. Latino-Am. Enfermagem. [Internet] 2009;17(1) [acesso em 10 jun 2012]. Disponível: http://dx.doi.org/10.1590/S010411692009000100007.

19. Verplancke T, De Paepe P, Calle PA, De Regge M, Van Maele G, Monsieurs KG. Determinants of the quality of basic life support by hospital nurses. Resuscitation. [Internet] 2008;77(1) [acesso em 29 mar 2013]. Disponível: http://www.resuscitationjournal.com/ article/S0300-9572(07)00570-9/pdf

20. Källestedt MLS, Rosenblad A, Leppert J, Herlitz J, Enlund M. Hospital employees'theorethical knowledge on what to do in an in-hospital cardiac arrest. Scand J Trauma Resusc Emerg Med. [Internet] 2010;18(43) [acesso em 29 mar 2013]. Disponível: http://www.sjtrem.com/content/18/1/43 